\section{Computer model of the interaction of human TFPI-2 Kunitz-type serine protease inhibitor with human plasmin}

\section{Dear Sir,}

Tissue factor pathway inhibitor-2 (TFPI-2) is a $32-\mathrm{kDa}$ serine proteinase inhibitor that strongly inhibits trypsin, plasmin, factor XIa and plasma kallikrein [1], and is mainly associated with extracellular matrices [2]. By inhibiting plasmin, TFPI-2 thus efficiently decreases activation of several metalloproteinases [2] and reduces tumor invasion and metastasis $[3,4]$. In addition, TFPI- 2 can also regulate plasmin in atherosclerotic plaques by modulating extracellular proteolytic mechanisms [5]. TFPI-2, which is a member of the Kunitz-type serine proteinase inhibitor family, consists of three tandemly repeated Kunitz-type domains, the first of which (K1) exhibits similarities in amino acid sequence to TFPI-1 and bovine pancreatic trypsin inhibitor (BPTI) (45\% and 40\%, respectively). The inhibition of serine proteinases by Kunitz-type inhibitors involves their binding to $\mathrm{K} 1$ and $\mathrm{P} 1$ residue that interacts with the proteinase pocket previously identified to be an arginine or a lysine residue [6-9]. Using site-directed mutagenesis experiments, Kamei et al. [10] reported that a TFPI-2 mutant with glutamine substituted for arginine lost its inhibitory activity towards trypsin and plasmin. Several structures showing the interaction of one serine proteinase with a Kunitz-type inhibitor, i.e. thrombin with BPTI [6], factor $\mathrm{Xa} / \mathrm{VIIa}$ with TFPI-1 [7,8] and alpha-chymotrypsin with BPTI [9], have been determined crystallographically. However, TFPI-2 structure and plasmin complexed with a Kunitz-type inhibitor have not to date been described. This report is the first to address the structural basis for molecular recognition of plasmin by the K1 domain of TFPI-2 (TFPI$2 / \mathrm{K} 1$ ). The 3D models of TFPI-2/K1 was built using the automatic comparative modeling server swissPDB (http:// www.expasy.org). The structure of TFPI-1/K2 (44\% identity with TFPI-2/K1 in 55 residues) was used as template to determine TFPI-2/K1. The resulting model was further energy-minimized using the steepest descent algorithm (SYBYL 6.9, Tripos, http://www.tripos.com), the atoms of the backbone being constrained during this step, and unconstrained using the conjugate gradient algorithm until the maximum derivative was $<0.1 \mathrm{kcal} / \mathrm{mol} / \AA$. After checking the stereochemical quality (WHATIF, http://www.cmbi. kun.nl/), all parameters were good for ensemble structure. The TFPI-2/K1 model and plasmin (coordinates extracted from the PDB file $1 \mathrm{bml}$ ) were superimposed on the $\mathrm{C} \alpha$ atoms of the TFPI-1/trypsin complex (coordinates extracted from the PDB file 1tfx). Finally, the few atoms that overlapped at the complex interface were relieved by energy minimization. The electrostatic potentials of TFPI-2/K1 and plasmin were calculated with swissPDB viewer $3.7 \mathrm{~b}$ software and using formal charges at $\mathrm{pH} 7.4$ (arginine, lysine, $\mathrm{N}$-terminus, +1; glutamate, aspartate and the C-terminus, -1 ; and histidine, neutral), ionic strength in the aqueous environment of $0.15 \mathrm{M}$ and dielectric constant of 80 . The three-dimensional structure of TFPI-2/K1 exhibited the typical Kunitz-type proteinase inhibitor folding, i.e. a double-stranded anti-parallel $\beta$-sheet from Arg20 to Phe33, and an $\alpha$-helix from Trp48 to Ala54. The core of the domain, comprising the secondary structure elements and the three disulfide bonds, was highly conserved. TFPI-2/K1 exhibited the same overall fold as BPTI [6] and TFPI-1/K2 [7], with rms deviations (root-mean-square) for all $55 \mathrm{C} \alpha$ atom positions of 0.70 and $1.09 \AA$, respectively. These values are in agreement with the $40 \%$ identity with BPTI and $45 \%$ identity with TFPI-1/K2. The binding loop of TFPI-2/K1 (Leu19-Tyr33) was in direct contact with the active site of plasmin involving the characteristic main-main conformational and intermolecular hydrogen bond interactions of canonical binding proteinase inhibitors [7-9]. Indeed, as shown in Table 1 , TFPI-2/K1 residues positioned close to the active site of plasmin $\left(\mathrm{P}^{\prime} 2, \mathrm{P}^{\prime} 1, \mathrm{P} 1\right.$ and $\mathrm{P} 3$ residues) were involved in hydrogen bonds. As compared with the TFPI-1/trypsin complex [7], two additional hydrogen bonds were found at the interface between TFPI-2/K1 and plasmin, probably improving the complementarity between the two molecules. The side-chain of TFPI-2 P1 residues (Arg15) extended into the plasmin-specific pocket, with its guanidinium group forming a salt bridge with the carboxylate group

Table 1

Predictive hydrogen bonds formed between TFPI-2/K1 and plasmin

\begin{tabular}{|c|c|c|c|c|c|}
\hline \multirow[b]{2}{*}{$\mathrm{P}^{\prime} 2$} & \multicolumn{3}{|c|}{ TFPI-2 K1 } & \multirow{2}{*}{$\begin{array}{l}\text { Plasmin } \\
\text { Gly }_{216}\end{array}$} & \multirow{2}{*}{$\begin{array}{l}\text { Dist }(\AA) \\
3.11\end{array}$} \\
\hline & $\mathrm{Pro}_{13}$ & $\mathrm{O}$ & $\mathrm{N}$ & & \\
\hline $\mathrm{P}^{\prime} 1$ & $\mathrm{Cys}_{14}$ & $\mathrm{O}$ & NE2 & $\mathrm{G} \ln _{192}$ & 2.57 \\
\hline \multirow[t]{9}{*}{$\mathrm{P} 1$} & $\operatorname{Arg}_{15}$ & NH1 & OD1 & $\mathrm{Asp}_{189}$ & 2.72 \\
\hline & & & OD2 & $\mathrm{Asp}_{189}$ & 4.15 \\
\hline & $\operatorname{Arg}_{15}$ & $\mathrm{NH} 2$ & $\mathrm{O}$ & Gly $_{218}$ & 3.60 \\
\hline & & & OD2 & $\mathrm{Asp}_{189}$ & 4.09 \\
\hline & $\operatorname{Arg}_{15}$ & $\mathrm{NE}$ & $\mathrm{O}$ & Gly $_{218}$ & 4.45 \\
\hline & & & $\mathrm{O}$ & Gly $_{216}$ & 3.15 \\
\hline & $\operatorname{Arg}_{15}$ & $\mathrm{~N}$ & $\mathrm{O}$ & $\operatorname{Ser}_{214}$ & 3.28 \\
\hline & & & OG & $\operatorname{Ser}_{195}$ & 3.82 \\
\hline & $\operatorname{Arg}_{15}$ & $\mathrm{O}$ & $\mathrm{NH}$ & Gly $_{193}$ & 2.85 \\
\hline P3 & $\mathrm{Leu}_{17}$ & $\mathrm{~N}$ & $\mathrm{O}$ & $\mathrm{Phe}_{41}$ & 2.80 \\
\hline
\end{tabular}



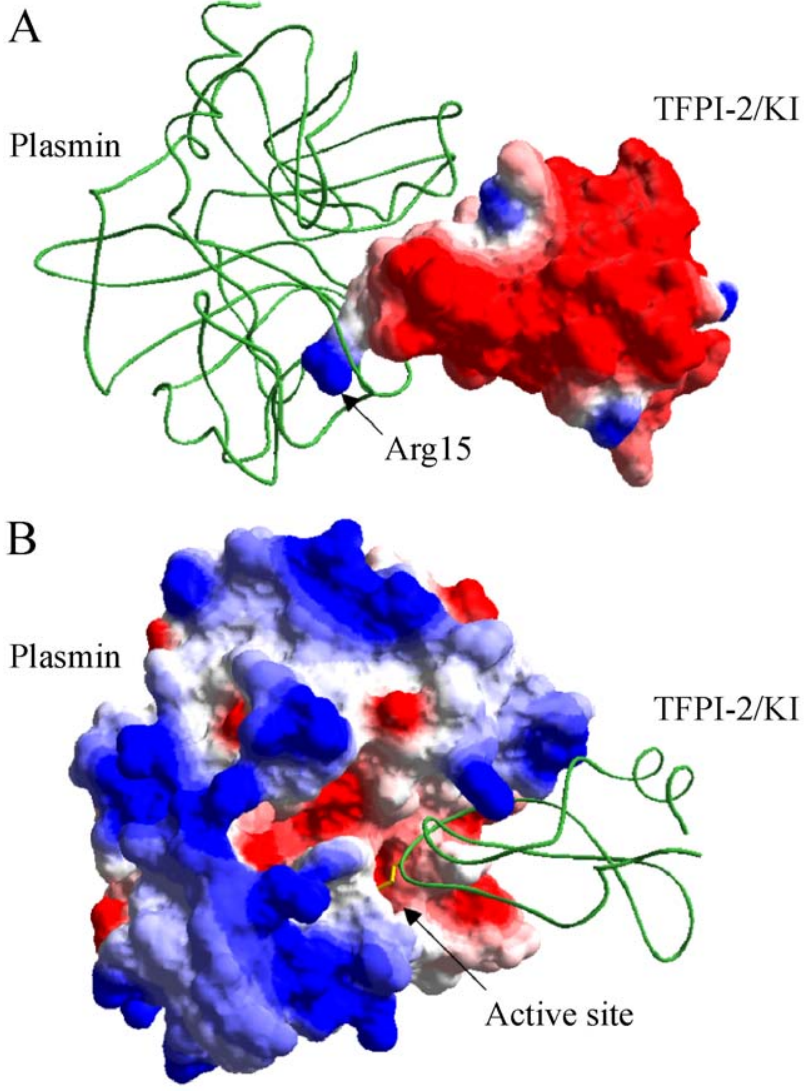

Fig. 1. Schematic representation of electrostatic surface of TFPI-2/K1 and plasmin structures. (A) Plasmin and TFPI-2/K1 complex showing plasmin as a green ribbon and the electrostatic potential surface of TFPI-2/K1 colored from dark blue (most positive) to red (most negative) using SPDB viewer 3.7b software. The P1 residue (Arg15) is indicated by an arrow. (B) Plasmin and TFPI-2/K1 complex showing $\mathrm{Ca}$ of TFPI-2/K1 as a green ribbon and plasmin colored as the electrostatic potential. The negatively charged surface located at the active site of plasmin is shown by an arrow and the side-chain of the P1 residue is colored yellow.

of Asp189, and was further stabilized through hydrogen bonds to Gly193, Ser195, Ser214, Gly216, and Gly218. As shown in Fig. 1, TFPI-2/K1 interacted with plasmin by presenting the positively charged $\mathrm{P} 1$ residue that was found in the complementarily negatively charged crevice of plasmin. In addition, the whole interaction was stabilized by the charge complementarity occurring at the TFPI-2/K1 and plasmin interface.

In conclusion, a new model of interaction between a serine proteinase, plasmin and a Kunitz-type serine proteinase inhibitor, TFPI-2, was constructed. The results emphasize the importance of the TFPI-2/K1 domain, and particularly the involvement of P1 residue (Arg15) for its interaction with plasmin. Further mutagenesis studies will be very valuable to characterize the role of each amino acid involved in hydrogen bonds and thus in complex stabilization. In addition, these complementary investigations might also contribute to the design of new drugs with potentially inhibitory effects on the migration of tumor cells.

\section{Acknowledgements}

The authors thank Doreen Raine for editing the English text. This study was supported by the Institut pour la Recherche sur la Thrombose et l'Hémostase in Tours, France.

\section{References}

[1] Petersen LC, Sprecher CA, Foster DC, Blumberg H, Hamamoto T, Kisiel W. Inhibitory properties of a novel human Kunitz-type protease inhibitor homologous to tissue factor pathway inhibitor. Biochemistry 1996;35:266-72.

[2] Rao CN, Mohanam S, Puppala A, Rao JS. Regulation of ProMMP-1 and ProMMP-3 activation by tissue factor pathway inhibitor- $2 /$ matrixassociated serine protease inhibitor. Biochem Biophys Res Commun 1999;255:94-8.

[3] Konduri SD, Rao CN, Chandrasekar N, Tasiou A, Mohanam S, Kin $\mathrm{Y}$, et al. A novel function of tissue factor pathway inhibitor-2 (TFPI-2) in human glioma invasion. Oncogene 2001;20:6938-45.

[4] Rao CN, Lakka SS, Kin Y, Konduri SD, Fuller GN, Mohanam S, et al. Expression of tissue factor pathway inhibitor 2 inversely correlates during the progression of human gliomas. Clin Cancer Res 2001;7:570-6.

[5] Herman MP, Sukhova GK, Kisiel W, Foster D, Kehry MR, Libby P, et al. Tissue factor pathway inhibitor-2 is a novel inhibitor of matrix metalloproteinases with implications for atherosclerosis. J Clin Invest 2001;107:1117-26.

[6] van de Locht A, Bode W, Huber R, Le Bonniec BF, Stone SR, Esmon CT, et al. The thrombin E192Q-BPTI complex reveals gross structural rearrangements: implications for the interaction with antithrombin and thrombomodulin. EMBO J 1997;16:2977-84.

[7] Burgering MJ, Orbons LP, van der Doelen A, Mulders J, Theunissen HJ, Grootenhuis PD, et al. The second Kunitz domain of human tissue factor pathway inhibitor: cloning, structure determination and interaction with factor Xa. J Mol Biol 1997;269:395-407.

[8] Bajaj MS, Birktoft JJ, Steer SA, Bajaj SP. Structure and biology of tissue factor pathway inhibitor. Thromb Haemost 2001;86:959-72.

[9] Capasso C, Rizzi M, Menegatti E, Ascenzi P, Bolognesi M. Crystal structure of the bovine alpha-chymotrypsin: Kunitz inhibitor complex. An example of multiple protein:protein recognition sites. J Mol Recognit 1997;10:26-35.

[10] Kamei S, Petersen LC, Sprecher CA, Foster DC, Kisiel W. Inhibitory properties of human recombinant $\operatorname{Arg} 24 \rightarrow$ Gln type-2 tissue factor pathway inhibitor (R24Q TFPI-2). Thromb Res 1999;94:147-52.

F. Hubé

P. Reverdiau*

S. Iochmann

Y. Gruel

Laboratoire d'Hémostase, EA 3249 "Cellules

Hématopoiétiques, Hémostase et Greffe”, IFR 120 Faculté de Médecine, 2 bis Bd Tonnellé, 37032

Tours Cedex, France

E-mail address: reverdiau@med.univ-tours.fr

8 September 2003

* Corresponding author. Tel.: +33-2-47-36-60-83; fax: +33-2-47-3660-95. 